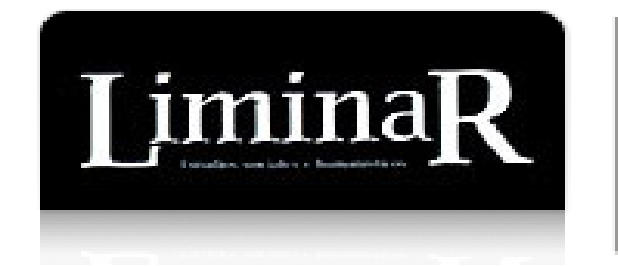

LiminaR. Estudios Sociales y Humanísticos

ISSN: $1665-8027$

liminar.cesmeca@unicach.mx

Centro de Estudios Superiores de México y

Centro América

México

García Zambrano, Ángel Julián

Frondas boscosas y parajes rocallosos: determinantes ambientales en los asentamientos indígenas

de Mesoamérica colonial

LiminaR. Estudios Sociales y Humanísticos, vol. VII, núm. 1, junio, 2009, pp. 3-13

Centro de Estudios Superiores de México y Centro América

San Cristóbal de las Casas, México

Disponible en: http://www.redalyc.org/articulo.oa?id=74516316002

- Cómo citar el artículo

- Número completo

- Más información del artículo

- Página de la revista en redalyc.org

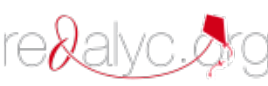

Sistema de Información Científica

Red de Revistas Científicas de América Latina, el Caribe, España y Portugal

Proyecto académico sin fines de lucro, desarrollado bajo la iniciativa de acceso abierto 


\title{
FRONDAS BOSCOSAS Y PARAJES ROCALLOSOS: DETERMINANTES AMBIENTALES EN LOS ASENTAMIENTOS INDÍGENAS DE MesoAmÉRICA COLONIAL
}

\author{
Ángel Julián García Zambrano
}

Resumen: Frondas boscosas y parajes rocallosos aparecen registrados con tal frecuencia en documentos coloniales tempranos alusivos a sucesos fundacionales infiltrados de simbólicas lecturas, que en este trabajo se presenta la probable interdependencia entre paisaje ritualizado y asentamiento. En este contexto la propuesta analiza las refundaciones de Pueblos de Indios realizadas por los españoles en el siglo XVI, junto a sitios donde todavía se recordaba una ocupación ancestral teñida de reminiscencias primordiales.

Palabras clave: ritualidad-paisaje-asentamiento

Enviado a dictamen: 16 de febrero de 2009 Aprobación: 25 de mayo de 2009

Revisiones: 1

Ángel Julián García Zambrano, doctor en Historia del Arte por la Universidad de Nuevo México, Albuquerque, New Mexico, coordinador del Cuerpo Académico "Determinantes del paisaje en la arquitectura prehispánica y colonial de México". Temas de especialización: cognitividad del paisaje cultural de Mesoamérica, trasposiciones del paisaje en la arquitectura prehispánica de México. Correo electrónico: cucurbita@prodigy.net.mx.
Abstract: Dense woods and rocky environments are recorded so frequently inearly colonial documents, as indicative of foundational events permeated with symbolic readings, that in this work a possible interdependence between landscape and settlement is suggested. In this context the proposal analyses the Spaniards' resettlement of Indian Towns nearby places where it was customary to recall an ancestral occupation infiltrated with primordial remembrances.

Key words: rituality-landscape-settlement

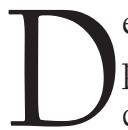
entro del legado documental de los textos y pinturas de las Relaciones geográficas y Mercedes de Tierras del siglo XVI abundan referencias a frondas boscosas y parajes rocallosos como el entorno donde preferentemente se habían asentado etnias emigrantes mesoamericanas que experimentaron la irrupción española en el territorio de México. Al percatarse de las emotividades ancestrales que enraizaban a la población local con este tipo de terruño, los españoles refundaron a los indígenas en sus cercanías a fin de preservar la integridad demográfica de sus comunidades. En este artículo se examinarán los datos que refieren la inclinación por poblar tales parajes, dadas las posibilidades de supervivencia que 
estos ecosistemas podían aportar. Simultáneamente se considerarán las connotaciones ideológicas asociadas a las percepciones que se tenía de dichos ambientes, las cuales actuaron como determinantes conceptuales influyentes en la decisión de fundarse.

"Montuoso y fragoso" y "arcabuco" o "arcabucal" representan las acepciones más empleadas en los documentos coloniales para referirse a los asentamientos establecidos donde la vegetación era densa y el terreno rocoso. De hecho, espesuras montuosas visualizadas hasta en el mismo fondo de las cañadas, eran asociadas con la presencia de mogotes o "pequeños cerros" de las vecindades; por lo que "arcabuco" y colinas boscosas devinieron en la mentalidad indígena en referentes sinónimos. Por ejemplo, en la Relación de Cuahuitlan en la Mixteca, se equiparan las espesuras entre manantiales del fondo de las cañadas con mogotes o "pequeños cerros" (Acuña, 1984: 130). ${ }^{1}$ El documento consigna que la impresión de colinas boscosas era generada por la fronda de vegetación denominada "arcabuco", circunstancia explícita en el mismo texto: "Cuauhitlan quiere decir, en [la] lengua que los naturales hablan, que es la mixteca, yonoyuto y, en la mexicana, cuauhuitlan, que lo uno y lo otro quiere decir 'espesura de montes', a causa de que son arcabucos muchos los que hay por los términos deste d[ic] ho pueblo" (Acuña, 1984: 130). ${ }^{2}$ Significativamente, los arcabucos del lugar se prolongaban hasta la franja litoral donde se encontraban lagunas o esteros estacionalmente comunicados por pasajes con el mar:

Cuahuitlan está metido en un poco de tierra montuosa, en sierras muy bajas y muy juntas a la mar [...]. Toda esta tierra, hacia la mar, está llena de esteros y lagunas, grandes y pequeñas [...]. Esta laguna, suele suceder, por tiempos, comunicarse con la mar a causa de que la tiene muy vecina y, por tiempos, se cierra en la seca con tanta arena que no le entra la mar (Acuña, 1984: 132-133).
Justlahuaca y Tecomaxtlahuaca en Oaxaca se poblaron a su vez en la vega de un encañonado río flanqueado por “... dos cerros altos, montuosos [...] y todo él está poblado de unos árboles de sauces, y cedros gruesos y altos" (Acuña, 1984: 282). Guauhtla, sujeto mazateco de Teutitlan, reseña el montuoso entorno donde fuera fundado el pueblo: "Su asiento es en una cumbre de un cerro casi llano, metido entre otros cerros [...]. Es tierra áspera, montuosa [...] sólo tiene un arroyo de agua, que pasa [a] media legua del pueblo. Tiene pocos pastos, por ser toda la t[ie]rra arcabuco" (Acuña, 1984: 207, 208). Vegetación densa y rala o la presencia de un frondoso árbol, también justificaron el asentamiento en poblado bajo las mismas premisas. Por ejemplo, los indígenas de Quiotepeque informaron haber preferido la falda de un cerro saturado de quiotes: "Quiotepeque [...], cabecera por sí, llámase ansí porque, en donde primero fundaron, [...] era junto a un cerro lleno de quiotes" (Acuña, 1984: 235). Tan significativa resultaba ser la referencia a la fronda vegetal del lugar, que a pesar de haber sido trasladado el pueblo a un lugar cercano por los frailes, preservaron la designación del lugar originario: “... y después, pasándose desotra parte del río [a] media legua, llamóse, como el propio antiguo, Quiotepeque" (Acuña, 1984: 235). En Tute[te]petongo, situado a tres leguas del famoso Apoala, la presencia de un enorme sabino o ahuehuete en el comedio de una agreste loma, dio el nombre al asentamiento (Acuña, 1984: 154). ${ }^{3}$ En Michoacán, tres poblados ocuparon un sistema encañonado de quebradas donde el arcabuco colgante de las rocas y lo accidentado del terreno solamente permitían el acceso por el lado oeste:

Están poblados en un llano, cerca los unos [pueblos] de los otros como [a] cuarto de legua, metidos en un monte arcabucal que, por la parte del sur, oriente y norte, están metidos en monte; sólo por la parte del poniente están algo desavahados [...]. Los del pueblo de Alimanzi [...] están metidos más a la tierra 
en la cañada, en un llano, desavahados de monte y arcabuco[...]. En estos tres pueblos de Alimanzi, Cuzcacuauhtla y Epatlan, en las montañas, valles y quebradas de todos sus términos, hay muy gran cantidad de árboles silvestres, que nacen por la mayor parte en los peñascos y albarradones más ásperos que son (Acuña, 1987: 146, 147, 151).

La persistencia de la difícil accesibilidad por lugares encañonados y quebrados hasta poder llegar a lo intrincado de los sitios dentro de las cañadas, se ejemplifica de modo realista en el pueblo de Motín en Michoacán: “... está metido en un río muy arenoso [...] y van por el río arriba hasta llegar al pu[ebl]o. El cual está rodeado de cerros arenosos y arcabucosos, llenos de quebradas y quebradillas [y] picos de cerros" (Acuña, 1987: 171). Maruata en el occidente de México, enfatiza ser este esquema el modo más conveniente de poblamiento: "Maruata está situado en un arcabuco en un poco de llano que allí hay junto al mar [...]. Tiene un humedal cerca de sí [...] y es lugar ahogado, y el mejor que por alli se hallóp [ar]a poblarlo" (Acuña, 1987: 173).

En el área maya de Guatemala, la frondosidad boscosa en la que se ubicaban los pueblos influyó en lo llamativo que a los españoles les pareció que "de ningún pueblo [...] se puede ver otro [...] hasta dar en él". ${ }^{4}$ San Andrés, sujeto de Atitlán, ejemplifica el modo de poblamiento: “... es todo el sitio rodeado de montañas altas de diferentes arboledas silvestres, y barrancas y honduras. En este pueblo no hay sabanas rasas". ${ }^{5}$ Fray Francisco Ximénez describe conjuntamente el modo extendido de poblar dictado por la preferencia a asentarse en terreno agreste, la forma de organización social inherente al esquema y la conformación urbanística que funcionalmente les correspondía:

... que lo demás del tiempo lo pasaban en sus casas que cada uno tenía en sus heredades, que fue el modo que los indios tuvieron de vivir en sus tierras y milpas, que jamás si no es en muy rara parte, tuvieron población en forma, sino en paraje donde hallaban oportunidad de tierras buenas, que esto era regularmente en los bajíos y quebradas, vivía una familia ó chinamital, no todos juntos en uno, sino cada uno en su milpa. Y estos tenían su cabeza de toda aquella parentela, como la tienen el día de hoy, y estos estaban sujetos á los Señores ó Caciques, que eran los grandes, y por esto aqueste género de poblaciones se llamaban Amac, que quiere decir como pierna de araña, ó que ha estendido como pierna de araña (Ximénez, 1926: 102).

Empero, debido al antagonismo planteado por la implementación del modelo reticular introducido por los españoles en espacios necesariamente abiertos, se originaron "pueblos viejos" que permanecieron en los originarios lugares intrincados. ${ }^{6} \mathrm{El}$ "asiento viejo" de San Andrés Atitlán se caracterizaba por la presencia de abundantes cañas negras o xahuactles, además de una gran ceiba en cuyo contorno se organizaba a una plaza junto a la pirámide o cú. ${ }^{7}$ Tan agreste era el paraje del "asiento viejo", que los frailes decidieron mudarlo a los predios de una llanada a fin de poder adoctrinar a los indígenas. ${ }^{8}$ En otro sujeto de Atitlán denominado San Francisco, la presencia del entorno montuoso, fragoso y agreste justificó el traslado a lugar “... asentado en pueblo, formado por sus calles y plazas según la orden de los pueblos de los españoles, y su iglesia en medio". 9

A tenor parecido correspondieron las decisiones de los españoles en el Corregimiento de Motín y Pomaro, descritas en la Relación de Michoacán, mismas que exigían de los indígenas “... que estuviesen en quebradas y arcabucos y lugares no acomodados [...] los sacase[n] de allí y los poblasen en partes y sitio de bu[en]os asientos, donde pudiesen ser visitados de sus curas y religiosos y de las justicias de su Majestad" (Acuña, 1987: 158). Tales desarraigos compulsivos causaron la caída demográfica que distinguió a la primera mitad del siglo XVI novohispano: "Costó a muchos indios e indias las vidas, por sacarlos, como se sacaron, de sus 
rincones y naturaleza, a otras aguas y asientos nuevos" (Acuña, 1987: 158).

La inexistencia de frondas boscosas en formaciones serranas compuestas por accidentadas faldas y cañadas, encontraron sustitutos adecuados en las regiones planas y semi-áridas de Yucatán. Montuoso y fragoso aludían allí a aislados árboles en medio de cenotes o a la típica vegetación mediana pero muy densa de sus contornos. Pixoy y Dzitnup ilustran la modalidad: "Llamóse Pijoy [Pixoy] el dicho pueblo porque sobre el cenote y aguada donde beben estaba un árbol que se llama Pijoy” (De la Garza, 1983: 51). Dzitnup “... estaba sobre el cenote y aguada donde beben una palma que acá llamamos cocoyol y en lengua de los dichos indios se llama mop, y a esta causa le nombraron Citmop [Dzitnup]" (De la Garza, 1983: 59). Topónimos como el de Ixmul conjuntaban la densidad de vegetación y los cenotes con la presencia de pirámides recordadas por los informantes indígenas que nutrieron las Relaciones histórico geográficas de la Gobernación de Yucatán: "La significación del nombre de Ixmul [Ichmul] es cosa montuosa y fragosa y de muchos edificios que antiguamente había y hasta ahora los hay [...], tiene dos cenotes a manera de pozos de Castilla, muy hondables" (De la Garza, 1983: 298). Los españoles supieron aprovechar las ventajas que representaba este tipo de ambiente natural en sus propias fundaciones. De allí que en Valladolid: “Fundóse el pueblo de los españoles en unos prados cercados de mucha maleza de piedra y arboleda silvestre [...]; de su nacimiento sitúase en medio de dos cenotes de agua dulce [...] tienen [...] cada uno de estos cenotes tres o cuatro bocas por donde sacan agua los naturales" (De la Garza, 1983: 34, 35).

La interdependencia saturada de referentes contraintuitivos en los arcabucos, se percibe en los casos donde los informantes indígenas pudieron consignar trazas de cognitividad indicativas de la peculiar forma de asentarse. Por ejemplo, lo agreste de una arbolada sierra justificó la construcción de un cú, pirámide o santa cale (de calli, "casa"), teopan o "iglesia" en Tilan- tongo: “... está una sierra hacia la parte del poniente, muy grande y de mucha arboleda, la cual llaman [...] teopantepeque y, en castellano, "sierra de iglesia"” (Acuña, 1984: 235). En Huehuetlan, la frondosidad arbolada de una "quebrada muy honda" junto a un cerro denominado "Tlalocan" es descrita como "tierra de muchas casas de animales por ser tan montuosa, que no se puede andar por mucha partes a caballo [...] [y] debajo de todos estos árboles [...] está metido este pu[ebl]o, de grandes frescuras de arboledas" (Acuña, 1985: 208, 210). Apariciones de deidades junto a un árbol sagrado influyeron en el topónimo adoptado por Teoquauhtenco: “...le llamaban Teoqua[uh]ten[c]o, [...] [o] 'árbol de los dioses', porque, en aquellos tiempos, les aparecían al pie del d[ic] ho árbol muchos demonios, adonde le sacrificaban" (Acuña, 1985: 412). ${ }^{10}$ San Miguel Capulapan relacionaba su fundación con el recuerdo del portentoso manar del agua del medio de un árbol que dio nombre al poblado. Adicional a ello, los informantes indígenas reportaron que tan pronto se extinguió dicho árbol, cesó de brotar agua del manantial: "Se llama este pu[ebl]o San Miguel Capulapa[n], que, en lengua española, quiere decir 'árbol de cerezo que, del medio del d[ic]ho árbol, sale una fuente de agua'. Y [dicen] que este árbol ha muchos a[ñ] os que se secó y pereció, y el agua que dél manaba se secó y se perdió" (Acuña, 1985: 420). Evidencias de institucionalización de la cognitividad aquí tratada, fueron consignadas en la Relación de Chimalhuacan Atoyac. En ella se describen los ceremoniales a la deidad en el cerro que culminaban con el realce de la pirámide mediante una fronda de follaje vegetal:

Los ritos y ceremonias q[ue] antiguamente, en el tiempo de la infidelidad, usaban y hacían estos caciques y sus vasallos en sus templos, y cúes y casas de sacrificio que tenían hechos dentro en el pueblo, y en otros que tenían encima de este cerro [de] Chimalhuacan, era esta la manera: [...] hablaban con el ídolo de piedra que tenían, llamado Huitzilopochtli [...] y le enramaban el 
templo [...] con hojas de árboles, en señal de agradecimiento y reverencia (Acuña, 1985: 163).

Dentro de las causalidades inferenciales acotadas se incluyen las informaciones recogidas por Durán, respecto a manantiales que brotaban del pie de ahuehuetes o sabinos. El fraile los describe como "árboles muy grandes y coposos, de que los indios hacían mucho caso, por hallarse siempre a los pies de las fuentes, en lo cual fingían divinidad y misterio" (Durán, 1967: 173). ${ }^{11}$ La inserción ontológica e institucional de la fronda boscosa que distinguía a un reverenciado paraje agreste, parece corresponder a los trasuntos cognitivos extraíbles de los rituales conmemorativos de Tlaloc. Tanto el cerro a Tlaloc y la serranía en honor a la deidad (Tlalocan), como el oratorio construido en un patio rodeado de idolillos, se remitían directamente al accidentado paraje constituido por cerros y quebradas. Según Durán, el interludio entre rocosas sierras e idolillos representativos de cada uno de sus cerros, era de tal naturaleza, que el dispositivo de la efigie rodeada por ellos no era sino la transmutación de aquellos dentro de estos:

Llamaban el mesmo nombre de este ídolo a un cerro alto que está en términos de Coatlinchan y Coatepec [...]. Llaman hoy día a esta sierra Tlalocan, y no sabré afirmar cuál tomó la denominación de cuál: si tomó el ídolo de aquella sierra, o la sierra del ídolo. Y lo que más probablemente podemos creer es que la sierra tomó del ídolo, porque como en aquella sierra se congelan nubes y se fraguan algunas tempestades de truenos y relámpagos y rayos y granizos, llamáronla Tlalocan, que quiere decir "el lugar de Tláloc. En este cerro, en la cumbre de él, había un gran patio, cuadrado, cercado de una bien edificada cerca [...]. A una parte de este patio estaba edificada una pieza mediana [...], sentado en un estradillo, tenían al ídolo Tláloc, de piedra, a la manera que estaba en el templo de Huitzilopochtli. A la redonda de él había cantidad de idolillos pequeños, que lo tenían en medio, como a principal señor suyo, y estos idolillos significaban todos los demás cerros y quebradas que este gran cerro tenía a la redonda de sí. Los cuales todos tenían sus nombres, conforme al cerro que representaba; los cuales nombres hoy en día les duran, porque no hay cerro ninguno que no tenga su nombre. Y así, los mesmos nombres tenían aquellos idolillos que estaban a la redonda del gran ídolo Tláloc, acompañándole, como los demás cerros acompañan a la sierra (Durán, 1967: 82).

Cognitivamente dichos ceremoniales alcanzaban su punto culminante al procederse a la elaboración artificial de un bosque denominado tetzacualco: “... antes del día propio de la fiesta de este ídolo hacían un bosque pequeño en el patio del templo, delante del oratorio de este ídolo Tláloc, donde ponían muchos matorrales y montecillos y ramas y peñasquillos, que parecía cosa natural y no compuesta y fingida" (Durán, 1967: 86). Mendieta informa sobre la construcción artificial de montañas rocosas realzadas con vegetación boscosa, flores, frutas y musgo adherido para crear la impresión de una entidad viviente. Ello ocurría como parte de las escenografías creadas por los indígenas durante las fiestas de Corpus Christi y San Juan en Tlaxcala en 1538. El suceso religioso estuvo realzado por el otorgamiento a los tlaxcaltecas, por parte de la monarquía, del título de ciudad:

Una cosa muy de ver: tenían en cuatro esquinas o vueltas que se hacían en el camino, en cada una su montaña, y de cada una salía su peñón bien alto; y desde abajo estaba hecho como prado, con matas de yerba y flores, y todo lo demás que hay en un campo fresco, y la montaña, y el peñón tan a el natural como si allí hubiera nacido; era cosa maravillosa de ver, porque había muchos árboles, unos silvestres y otros de frutas, otros de flores, y las setas, y hongos, y vello que nace en los árboles de montaña y en las peñas, hasta los árboles viejos quebrados, a una parte como monte espeso y a otra más ralo; y en los 
árboles muchas aves chicas y grandes; había halcones, cuervos, lechuzas, y en los mismos montes mucha caza de venados y liebres, y conejos, y adives y muy muchas culebras; éstas atadas y sacados los colmillos o dientes porque las más de ellas eran de género de víboras [...]. Y porque no faltase nada para contrahacer a todo lo natural, estaban en las montañas unos cazadores muy encubiertos, con sus arcos y flechas [...]. Para ver estos cazadores había menester aguzar la vista, tan disimulados estaban y tan llenos de rama y de vello de árboles [...]. Este día fue el primero que estos tlaxcaltecas sacaron su escudo de armas, que el emperador les dio cuando a este pueblo hizo ciudad (Motolinía, 1971: 100-101).

Como podrá deducirse, la ritualizada escenografía constituía una miniaturización de los idealizados parajes cuyas significantes eran percibidas a lo largo de las migraciones. ${ }^{12}$ Elemento clave de la frondosidad ritualmente construida era la remembranza del árbol asociado a cuevas de origen que entre los mexica se materializaba en la figura de su símil llamado Tota, "nuestro padre". Por cuanto Tota aparecía rodeado de otros cuatro árboles más pequeños que se unían a su tronco por medio de mecates, resultan claras las alusiones a la fertilidad y descendencia materializadas en la figura del referido vegetal: "En medio de este bosque ponían un árbol muy grande y coposo y, alrededor de él, otros cuatro pequeños [...]. A este árbol ponían por nombre tota, que quiere decir 'nuestro padre', a causa de que, a la redonda de él, ponían otros cuatro más pequeños, quedando él como padre de los demás" (Durán, 1967: 86, 87). ${ }^{13}$ Consecuente con este concepto de mimética reproductividad son las imágenes ya mencionadas del cerro mayor que genera de su seno a eminencias menores. Aunado a las causalidades nucleares que registraban la presencia del umbral comunicativo con el inframundo acuático, representado en las orillas de lagos y lagunas (Aztlan), Tota era trasladado al sumidero de Pantitlan. Allí se le hacían desatar sus atadas ramas en un teatral artilugio cuyo efecto ulterior consistía en recobrar su frondoso aspecto, al entrar en contacto directo con el suelo cenagoso sobre el tepetate de la laguna:

Llegados, pues, a aquel lugar [de Pantitlan] [...] tomaban luego aquel árbol grande, Tota, e hincábanlo en el cieno junto al ojo de agua, o sumidero, tornándole a desatar las ramas y el acoparse [...]. El cual acabado y la ofrenda [de sacrificar a una niña que representaba a la laguna], con todas las demás cerimonias de hincar allí el árbol Tota, cesaba el tañer y el cantar y todos los demás regocijos, y con mucho silencio se volvían todos a la ciudad. Con lo cual fenecía la fiesta, aunque no las ceremonias que los labradores y serranos hacían en las labranzas y sementeras, y en los ríos y fuentes y manantiales" (Durán, 1967: 88, 89).

Mientras los mexica trataban del modo explicitado el factor de frondosidad enunciada, las regiones costeras de Mesoamérica produjeron modalidades sobre la misma construcción cognitiva. En el cuestionario de las Relaciones geográficas se consignan casos donde lo boscoso es factor causal respecto a pares de islas o islotes separados por canales angostos de agua que dieron lugar a la denominación genérica de "isla partida". Común en la mayoría de esos ejemplos era la alusión a la hendidura o separación sugerente del instante del pasaje o cruce del umbral que con anterioridad se ha tratado. En Tlacotalpa llegó a consignarse de modo escueto esta asociación: "Tlacotalpa quiere decir 'tierra partida', y, ansí, está hecha una isla” (Acuña, 1985: 283). Zuthuthai fue el nombre de lugar elegido por los habitantes de Sotuta en Yucatán para designar la isleta en el interior de un cenote o "cueva" que llenaba la función y significados de la isla en medio de un gran lago o laguna:

El pueblo de Zotuta [Sotuta], que los indios llaman zututhai, que éste es su propio nombre, significa agua 
en círculo que tiene una isleta en medio, y de aquí tomó [la] denominación el pueblo. [...]. Y es así, que en este asiento tienen una cueva que tendrá más de cincuenta pies de hueco, y en medio tiene una isleta y la cerca el agua muy en redondo (De la Garza, 1983: 145-146).

También de orden fragmentario que no llega a referir el aspecto boscoso es el testimonio rendido por el Licenciado Diego García de Palacio, mediante carta al monarca español, tocante a las provincias de Guazacapán, los Izalcos, Cuzcatlan y Chiquimula en Guatemala. ${ }^{14}$ En ella describe que en Zenzonatl o "cuatrocientos ríos", había "una laguna en la falda del volcán [...]. Tiene dos isletas en medio. Los indios pipiles tenían esta laguna por un oráculo de suma autoridad y que ningún humano podía ver lo que en ella había [...]. Y derivaban esta devoción de patrañas antiguas". ${ }^{15}$

Mayor asociación inferencial respecto a lo boscoso se encuentra en el testimonio relativo a una isla arbolada frente a Veracruz, donde todavía en el siglo XVI ofrendaban peregrinos de lugares distantes en restos de pirámides u oratorios:

Desta isla de San Juan de Ulúa hacia el sureste, [a] legua y media, está una isleta alta en la que hay algunos árboles y yerbas, que se dice Sacrificios, en la cual dicen q[ue] los indios venían antiguamente a sacrificar, y [a] hacer sus ritos y gentilidades, como a lugar sagrado y de gran veneración. Hay en ella, ahora, algunas muestras de haber sido poblado, por haber unos paredones viejos, que dicen algunos ser el único altar en que los indios solían sacrificar (Acuña, 1985: 329).

De incidental pertinencia a la cognitividad esbozada era el conjunto de isletas cercanas a Ulúa que el médico español Diosdado reportara en los siguientes términos: "Por entre todas estas isletas hay canales muy hondas [...] por donde pueden pasar navíos de alto bordo [y] mucho porte" (Acuña, 1985: 330). Algunas de estas islas eran identificadas por su color verde "... porque de lejos parece deste color por las muchas ovas, y yerbecillas y cañas que en ella hay". ${ }^{16}$ La pintura que acompaña a la Relación de Veracruz muestra el par de pequeñas islas que por su configuración alargada delineaban el aludido pasaje. ${ }^{17}$ Similarmente, la Relación de Compostela ilustra y describe un par de islas donde también era intensa la actividad ceremonial desplegada: "A la boca de la bahía, a la punta de Tintoque, hay [...] dos isleos q[ue] están de tierra como [a] cuatro leguas; uno del otro, [a] media legua. Son pequeños [...]. Antiguamente solían ser sacrificadero de indios, e iban a adorar allí al Diablo". ${ }^{18}$

Regiones mediterráneas dotadas de lagos o ríos, peñascosas islas o cumbres dotadas de conspicuos tajos, contenían trasuntos cognitivos parecidos. El ambiente del lago Atitlán en Guatemala se ajustaba al aparente requisito paisajístico: "Tiene por toda la orilla gran cantidad de peñascos grandes y piedras, y algunas islas dentro della propia. Y principalmente hay dos, que tendrán de circuito cada una media legua [...]. Críase alrededor de ella mucha enea. Estas islas son de poco suelo, por ser todas peñas quebradas y partidas entre sî". ${ }^{19}$ Según Burgoa, Quijecolaani es sitio serrano zapoteca seleccionado por los seguidores del gobernante Quegolani, por divisarse “... un risco altísimo partido que le haze espaldas [a la sierra] [...] y le pusieron por [tal] nombre [por] que significa peña tajada o risco quebrado". ${ }^{20}$ Dicha prominencia era vista por los indígenas estrechamente asociada con el río de las inmediaciones, circunstancia determinante en el patronímico adoptado por el gobernante del lugar. ${ }^{21}$

Tocante a la veta ontológica que subyace en éstos y otros testimonios suministrados por los indígenas, se considerarán las funciones religiosas realizadas en este tipo de entorno natural. "Corazón de reino" fue la denominación recabada por los españoles al arribar al sitio zapoteca de Guixipecocha en el istmo de Tehuantepec, respecto a una isla dotada de la mayoría 
de referentes tratados hasta ahora como indicativos de cognitividad primordial: islote peñascoso, cueva y manantial, efigie reverenciada en pirámide junto a arboleda boscosa y arribo a laguna en canoas para realizar ceremoniales pertinentes. Acorde a Burgoa, el paraje se encontraba en las cercanías “... de un arroyo [y] un peñasco, de hasta quinze, ó veinte estados de alto, y cerca de la cumbre, vna prodigiosa figura de tiempo inmemorable de su antigüedad". ${ }^{22}$ En dicho lugar ofrendaba el gobernante Cocijopij “... al ídolo mayor, q' llamaban corazón del reyno, y lo tenían en una isletilla, como Cue grande, con arboleda muy fresca, y de mucha caza de conejos, y en medio una grande cueva, y alrededor la grande laguna de S. Dionisio al presente, para donde se embarcaban en canoas, ó barcos, acabado el sacrificio". 23

Concomitante con los trasuntos aquí desplegados, los dominicos pudieron erigir un nuevo convento en las inmediaciones costeras del istmo de Tehuantepec, aprovechando la cesión que les hiciera el gobernante zapoteca de un sitio dotado de parecidas características:

\section{... dándonos sus huertas, y baños de recreo, en el lugar de Laoyaga, assi llamado en su lengua, tal es el sitio que allí puso la naturaleza, con unos manantiales de agua tan crystalina, y pura, que es admiración, brota al pie de un arbolaso muy copado, de entre sus rayzes, arrimado á un cerrillo pedregoso, y nace por dos ojos hermosos á borbollones, formando inmediatamente una alberca, como de dos brasas en circunferencia, y una vara de fondo de donde se desata en un arroyo. ${ }^{24}$}

Burgoa también informa sobre la existencia de un paraje de asentamiento huave, distinguido por el "cerrillo arbolado", la laguna entre estrechos de tierra que figuraban isletas, dotada ella de una barra reguladora de reflujos del agua, además de la respectiva cueva donde se veneraba a un "Corazón de pueblo" a quien se impetraba por lluvia:
Los huabes [...] recien llegados a esta tierra [de Tehuantepec], segun lo mas probable, por la mar en barcos, ó valzas [...] no descubrieron otra mas desembarazada, ó parecida á la suya, que esta, [...] no havian perdido las noticias de la marinería de sus antepasados, y recogiendose [...] entre unas lagunas grandísimas, passando por un estrecho de tierra [...], la una es tan grande y con las crecientes, y menguantes, sube, y baxa poderosamente; en esta laguna á un lado está vn cerrillo aislado muy ameno, y poblada de arboleda, y animales, y aquí está vna profunda y dilatada cueva donde el Zapoteco tenía vn Idolo de su mayor veneración, y la llamaba el Alma, y Corazon del Reyno [...] y de su favor [de]pendian [...] [los] buenos temporales con que lo sustentaba ....25

\section{Conclusión}

Las fuentes etnohistóricas del siglo XVI en México evidencian diversidad de cognitividades referencialmente empleadas por las etnias emigrantes mesoamericanas, cuando era su propósito localizar lugares para asentarse. Dentro de esta conceptualización se demostraba preferencia por ocupar lugares rocallosos donde brotaban manantiales en medio de verdeantes frondas boscosas. De hecho, esta combinación de elementos ambientales contribuyó a la generación de una matriz de imagen sobre la portentosa proveniencia del interior acuático primordial. Documentada en clásicas escenas como la del mural de Tepantitla en Teotihuacan (mural popularmente llamado "Tlalocan"), se cuenta además con su persistencia eidética registrada oralmente en las Relaciones Geográficas del siglo XVI. En ocasiones la protagonista del afloramiento es una serpiente que durante el PosClásico encarnó a la mismísima imagen de Quetzalcoatl. El hecho se reporta en la Relación Geográfica de Motines, donde se consigna que la mayoría de los poblados encontrados por los españoles en la zona se localizaban en arcabucos rocosos o espesuras de 
muy difícil acceso. Tal circunstancia contrastaba con la conceptualización de ciudad europea que valoraba exclusivamente los terrenos de condición regular y accesible. De allí que el redactor de la citada Relación (Juan Alcalde de Rueda), reportara la inaccesibilidad de los asentamientos de la cuenca de Tlatictla y Motin por encontrarse dentro de la angostura de un arenoso río, "el cual está rodeado de cerros arenosos y arcabucosos, llenos de quebradas y quebradillas [y] de picos de cerros" (Acuña, 1987: 171). Empero, la notable persistencia por asentarse en dicho entorno devenía de la identificación que hicieron los pobladores de Tlatictla de un área que asociativamente llamaron Borbitni o "lugar de plumas". Aunque los frailes se esforzaron por reasentar a los indígenas en traza ad hoc, perseveraron en su antigua costumbre de permanecer extendidos y en las cercanías del nacimiento del accidentado río. La razón de la preferencia superaba el mero requerimiento del abastecimiento de agua, como bien pudieran argumentar algunas corrientes de la antropología y arqueología contemporáneas (materialistas y neoprocesualistas). De hecho, el aquerenciamiento al sitio respondía a la portentosa aparición periódica de una serpiente que pensaban salía literalmente del ojo de agua del manantial. Aparte de ser ofrendada con mazorcas tiernas de maíz que el documento llama "jiotes" [sic por jilotes], su concurso era crucial en el suministro de plumas requeridas por los cabezas de linaje para los ceremoniales que socialmente aglutinaban al poblado. Obviamente, de esta interdependencia entre asentamiento y ritualizado paisaje donde se rememoraba la proveniencia del interior acuático primordial en la imagen de la serpiente, se produjo la adherencia existencial al sitio escogido para el poblamiento. De ello dio cuenta con mayúscula sorpresa el funcionario español encargado de sustanciar la respectiva Relación geográfica de Tlatictlay Motin. Por lo que a modo de conclusión estimamos justificado transcribir los pasajes pertinentes que permiten corroborar algunos de los trasfondos ideológicos subyacentes en los modos de selección del paisaje destinado a asentamiento en Mesoamérica:

La narración y cuento deste hecho es muy general en esta provincia, y aun fuera de ella, como cosa que pasó en hecho de verdad, lo cual oí contar muchas veces a muchos indios, y aun desde mi niñez. Y ahora, de nuevo, para escribirlo aquí, repreguntándolo, se afirman en ello [...]. Para ir al nacimiento deste río[de Tlatictla] desde Ihuitlan, en cuya vecindad está, van por el río arriba a embocar por unas peñas tajadas, debajo de las cuales, por la mucha angostura, sube el camino [...] por unos horados y estrechuras de peñas [...] y va a salir a un llano pequeño [donde] [...] está el ojo y fuente deste río susodicho [...]. En el nacimiento deste río, que está debajo de una peña grande, hace un estanque hondable o, como dicen, "ojo de agua". Y los naturales deste dicho río, y sus moradores, dicen que muy ordinariamente oían decir a sus padres y abuelos que, en tiempos de su gentilidad, había allí una gran sierpe o dragón, que salía del ojo de aquel agua, cuyo cuerpo tenía muy grande y, las alas, de plumas tenía muy ricas y doradas, y, en partes del cuerpo, de escamas grandes de conchas. Y [dicen] que le sacrificaban y daban de comer algunas veces indios jiotes, porque de aquestos comía y demandaba [...]; y que esto hacían con ayunos y abstinencias, porque el dragón les diese de las plumas ricas que tenía, y que después, servían a los principales de plumajes para sus fiestas y areitos, (Acuña, 1987: 176, 177).

\section{Notas}

1 "Esta tierra es toda rasa, respecto de algunos arcabucos pequeños que, en algunos arroyos y cañadas bajas, se hacen de cerros pequeños" (Acuña 1984: 130).

${ }^{2}$ En la nota 5, Acuña propone un significado más riguroso del topónimo: "entre árboles" o "lugar de muchos árboles” (Acuña, 1984: 130). 
3 "El asiento de este pu[ebl]o está en una loma agra: t[ien] e por nombre chamaco; tomó por apellido este nombre por un árbol grande, que se llama sabino" (Acuña 1984: 154).

${ }^{4}$ Relación de Zapotitlán, Guatemala, 1982: 41.

${ }^{5}$ Relación de Santiago Atitlán, Guatemala, 1982: 124.

${ }^{6}$ La fundamentación de esta propuesta en: García Zambrano, Ángel Julián "Pueblo nuevo y Pueblo viejo: Recuperación de una memoria urbana perdida" en La ciudad: problema integral de preservación patrimonial (Louise Noelle, ed., 2004: 59-82)

7 "Dicen estos indios que esta denominación tomó este pueblo antiguamente [Qui Ohg o Xahuac Tepetl], en la parte y lugar donde estaban poblados, porque en el patio dél estaba un grande cu donde hacían sus sacrificios al demonio y, en medio de una plazuela que había, estaba un árbol grande que llaman pochotl en mexicano y, en castellano, 'ceiba', y muchos de los xahuactles, que son unas cañas macizas, negras, de que se hacen hoy día bordones negros y lisos. Y, por esta razón, se llamó Xahuac Tepetl el asiento donde estaban asentados antiguamente en el asiento viejo" (Relación de Santiago Atitlán, Guatemala, 1982: 126-127).

8 “... de donde los sacaron los religiosos de San Francisco [...] porque, por estar poblados en montañas grandes de tierra áspera y fragosa, no los podían visitar para los doctrinar, y los pasaron al sitio adonde ahora están poblados" (Relación de Santiago Atitlán, Guatemala, 1982: 127).

${ }^{9}$ Relación de Santiago Atitlán, Guatemala, 1982: 139.

${ }^{10}$ Acuña propone que Tequauhtenco significa "en la orilla del árbol grande o divino (Acuña 1985: 412, nota 51).

${ }^{11}$ Durán también informa sobre la denominación que los indígenas le daban al ahuehuete de "atambor de agua", debida a "... el pasar el agua por sus raíces y por hacer un suave ruido con el aire la copa y ramas de él” (Durán, 1967: 173).

${ }^{12}$ Bernal García trata la recreación del jardín desértico en México-Tenochtitlan, como una evocación del paisaje de proveniencia mítica de las etnias que emigraron del norte al centro de México; véase "The Dance of Time, The Procesión of Space at Mexico-Tenochtitlan's Desert Garden" en Sacred Gardens and Landscapes: Ritual and Agency (Michel Conan, ed.), Dumbarton Oaks Colloquium on the History of Landscape Architecture, vol. 26, 2007.

${ }^{13}$ La selección de Tota en la montañosa sierra implicaba encontrar el más frondoso y uniforme árbol, cuyas ramas debían ser liadas cuidadosamente, a fin de evitar daño alguno durante su traslado. Preliminar al dramático despliegue de su frondosidad en Pantitlan, se lo liberaba de ataduras frente al Templo Mayor, previa colocación de su tronco en un hoyo excavado al propósito. Durán reporta que el efecto inmediato era el del renacimiento de Tota; véanse los detalles del ceremonial en Durán, I, [1570] 1967: 87.

${ }^{14}$ Expediente XX-2 de la Colección Joaquín García Icazbalceta, Nettie Lee Benson Latin American Library, Universidad de Texas, Austin; véase también la versión anotada de Acuña, ed., Guatemala, 1982: 263-287.

${ }^{15}$ Carta del Licenciado Palacio, Guatemala, 1982: 273. La misiva también reporta la existencia en San Salvador de una laguna que “... tiene en medio dos peñoles, en uno de los cuales los indios [...] hacían sus sacrificios e idolatrías" (Carta del Licenciado Palacio, Guatemala, 1982: 276).

${ }^{16}$ El texto refiere que dicha isla apenas se encontraba a media legua de distancia (Acuña, 1985: 330).

${ }^{17}$ No ilustrada por la condición de la fuente disponible.

${ }^{18}$ Relación de la ciudad de Compostela, Nueva Galicia, 1988: 95; véanse los islotes en la pintura de la Relación, los cuales forman estrecho pasaje debido a su posición paralela, justo en el acceso a la Bahía de Banderas y muy cerca de Temichoque, cuyo nombre significa "junto al agua"; 94-95.

${ }^{19}$ Relación de Santiago Atitlán, Guatemala, 1982: 92.

${ }^{20}$ Burgoa, 2 ${ }^{\mathrm{a}}$. Parte, t. II, 330v.

21 "Pusieron los Indios antiguos á este pueblo Quigolani, que quiere decir en su lengua, dentro de el río" (Burgoa, 2ª Parte, t. II, 330v).

22 Burgoa, 2a . Parte, t. II, 33lv. 
${ }^{23}$ Burgoa, 2a. Parte, t. II, 33lv.

${ }^{24}$ Burgoa, 2a. Parte, t. II, 386v.

${ }^{25}$ Burgoa, 2․․ Parte, t. II, 396r-397v.

\section{Bibliografía}

Acuña, René (Ed.) (1984-1988), Relaciones geográficas del siglo XVI, 10 vols., México: Instituto de Investigaciones Filológicas, UNAM.

Bernal García, María Elena (2007), "The Dance of Time, the Procesión of Space at Mexico-Tenochtitlan's Desert Garden", en Michel Conan (ed.) Sacred Gardens and Landscapes: Ritual and Agency, vol. 26, Dumbarton Oaks Colloquium on the History of Landscape Architecture.

Burgoa, Francisco de (1997), Palestra historial de virtudes y ejemplares apostólicos, México: Gobierno del Estado de Oaxaca, Miguel Ángel Porrúa.

De la Garza, Mercedes et. al. (Eds.) (1983), Relaciones de la Gobernación de Yucatán., 2 vols., México: Instituto de Investigaciones Filológicas, Centro de Estudios Mayas, UNAM.

Durán, Diego (1967), Historia de las Indias de Nueva España (escrita en el siglo XVI, cap. 1570), preparación de la edición paleográfica del original de Madrid de Ángel María Garibay K., 2 vols., México: Editorial Porrúa.
García Zambrano, Ángel Julián (2004), "Pueblo nuevo y pueblo viejo: recuperación de una memoria urbana perdida", en Louise Noelle (comp.), Memoria del IX Coloquio del Seminario de Estudio del Patrimonio Artístico: conservación, restauración y defensa. La ciudad: problema integral de preservación patrimonial, Estudios de Arte y Estética 56, México: Instituto de Investigaciones Estéticas y Facultad de Arquitectura, UNAM, pp. 59-82.

García Zambrano, Ángel Julián (2007), “Ancestral Rituals of Landscape Exploration and Appropriation among Indigenous Communities in Early Colonial Mexico"; en Michel Conan (ed.) Sacred Gardens and Landscapes: Ritual and Agency, vol 26, Washington: Dumbarton Oaks Colloquium On the History of Landscape Architecture, Harvard University Press, pp. 192-222.

García Zambrano et. al. (Coords.) (2006), Territorialidad y paisaje en el Altepetl del siglo XVI, México: Fondo de Cultura Económica.

Motolinia, o Toribio de Benavente (1971), Memoriales o libros de las cosas de la Nueva España y de los naturales de ellas, nueva trascripción paleográfica del manuscrito original, edición y estudio introductorio de Edmundo O' Gorman, México: Instituto de Investigaciones Históricas, UNAM. 